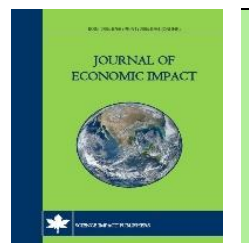

Available Online

Journal of Economic Impact

ISSN: 2664-9764 (Online), 2664-9756 (Print)

http://www.scienceimpactpub.com/jei

\title{
ASSESSING IMPACT OF BILLION TREE TSUNAMI PROJECT ON ENVIRONMENT AND LIVELIHOOD STRATEGIES: A CASE STUDY FROM DISTRICT FAISALABAD
}

\author{
Aqeela Saghir a, , Baber Shahbaz a, Muhammad Amjed Iqbal b, Sadia Ijaz a, Shoukat Ali a, Rakhshanda Kousar b, \\ Rana Muhammad Amir ${ }^{\mathrm{a}}$
}

a Institute of Agri. Extension Education and Rural Development, Univ. of Agriculture, Faisalabad, Pakistan ${ }^{b}$ Institute of Agri. \& Resource Economics, Univ. of Agriculture, Faisalabad, Pakistan

\section{ARTICLE INFO}

\section{Article history}

Received: August 12, 2021

Revised: October 30, 2021

Accepted: November 01, 2021

\section{Keywords}

BTTP

Livelihood

Environment

Pollution

Green Pakistan

KPK

\section{ABSTRACT}

The study aims to analyze the impact of the Billion Tree Tsunami Project on the environment and livelihood of the people. The main focus was to assess the impacts of this project in Faisalabad localities. For this purpose, primary data were collected through face to face survey, and respondents were selected by using the quota sampling technique. A total of 124 respondents were interviewed by using a structured questionnaire and analyzed through SPSS software. The results show that improved water storage capacity (Mean $=3.95$ and $\mathrm{SD}=0.927$, sustain ecosystem $($ Mean $=3.72$ and $\mathrm{SD}=0.98$ ) were ranked at the top by the respondents in assessing the impact of Billion Tree Tsunami Project (BTTP) on the environment. Moreover, the impact of BTTP was assessed by taking the perception of respondents on different attributes. It was observed that factor of labour opportunities was highly endorsed by the respondents. Every age group had almost the same perception of the impact of the billion trees tsunami project. The majority of the highly qualified people (postgraduation and above) had a more positive opinion about billion tree tsunami project as compared to those respondents who were less educated. The gamma statistic $(\lambda$ $=0.344, \mathrm{p}=0.010$ ) demonstrate a significant and positive relationship between the selected factors. It is concluded that Billion Tree Tsunami Project imprinted strong footings in Faisalabad district as in the overall country. Further, it was recommended that the BTTP project one of the best step to save the environment from the adverse impact of climate change.

\footnotetext{
*Email: aqeelasaghir@uaf.edu.pk

https://doi.org/10.52223/jei4012201

(C) The Author(s) 2022.

This is an open access article under the CC BY license (http://creativecommons.org/licenses/by/4.0/).
}

\section{INTRODUCTION}

Agriculture is the backbone of Pakistan's rural economy. Crops, vegetables, cattle, poultry farming, fruit farming, and forestation are all part of it. Forests play an important part in the growth of a country, and forestation is required on $25 \%$ of the land in Pakistan, even though this coverage is less than $5 \%$. In many industrialized countries, forestry is an important economic segment. Forests cover about one-third of the land area, similar to Germany. Wood is a renewable reserve resource that supports over a million jobs and provides billions in revenue each year (Kleinn et al., 2011).

Almost 200 million forest dwellers and poor immigrants rely on forests for survival (Angelsen et al., 1999). Approximately 1.6 billion people around the world rely on forests for their survival. Plants are beneficial in the treatment of a variety of ailments, including cancer, which is one of the most dangerous (Winter, 2000). Growing the forest helps to clean up the overall world's environment. Forests produce a range of resources, including grazing and browsing shrubs, firewood, trees, and grasses, fruit, medicinal herbs, wildlife, scenic splendor, and water springs. The forest is extremely important to the local population's well-being. Natural resources, such as forest production, were used to provide items for the rural community's existence. Wood, fruits, paper, and medicine are all provided by trees, and they play an important role in our existence. The rural inhabitants and their animals take a break in the shade, breathing oxygen from the forest. One tree is sufficient to offer necessary oxygen to a four-family household (Fomété and Vermaat, 2001). Forests are one of the most important sources of water, food, shelter, and other essentials in rural areas. Rural people have specific expertise in the use of local flora thanks to indigenous knowledge passed down through generations (Shinwari and Khan, 2000). Forests protect the environment and provide shelter for the global community. Increasing levels of anthropogenic stress, on the other hand, exerted a significant force on the forests. This necessitates direct management and maintenance of the 
region's natural reserve (Panigrahy et al., 2010). Because there is no endogenous switch, field afforestation measures have revealed strong regional and native attention. In some areas, the stages of arena afforestation have higher bounds of local reception, both in terms of the actual areas afforested and the effects of such afforestation on the native landscape (Selby et al., 2003).

In 2010, Punjab had a natural vegetation of 28.9 kilometers, or 0.14 percent of its entire land. In 2020, it lost 385 million hectares of forest, equivalent to 156 million tonnes of $\mathrm{CO}_{2}$. The growth of a country's GDP is linked to the growth of its forests. They are the only ones that have access to wood. Forests can limit wind erosion and reduce flood severity along river and canal banks. The use of fossil fuels is quickly growing, resulting in air pollution. Carbon Dioxide is absorbed by forests; after that forest releases oxygen (Ahmad et al., 2017). Afforestation of marginal areas not only benefits farmers financially but also benefits the ecosystem by reducing soil erosion, stabilizing dunes, regulating microclimates, and sequestering carbon (Nunes et al., 2011). Trees absorb and fix $\mathrm{CO}_{2}$ from the atmosphere during photosynthesis. They act as a carbon sink because they store carbon in the form of biomass. However, as trees age, are sick, and die, their net long-term $\mathrm{CO}_{2}$ storage dynamics alter (Nowak et al., 2013).

The Billion Tree Tsunami project spans three forest regions in KP: the southern forest (region 1), northern forest (region 2), and Malakand forest (region 3). The aim of planting one billion seedlings was met in 2017, and the forest service spent $\$ 47$ million in the third phase (2017-2020) to manage and protect the built assets (Khan et al., 2019). In 2014, Government launched the Green Growth Initiative (GGI) in Khyber Pakhtunkhwa (KPK) to mitigate the effect of increased deforestation, environmental degradation, and climate change (Government of KPK, 2015). The GGI aims to create a model of economic growth that is both environmentally friendly and adaptable to climate change. Forestry was one of the six intervention areas that were prioritized. The Billion Tree Tsunami Project (BTTP), the KPK National Parks project, and the Community Micro-Hydel project were among the forestry projects (Ashraf, 2019).

Setting a goal of 10 Billion Tree Plantation in Pakistan, including Punjab province, after the successful Billion Tree Tsunami Project (BTTP) by the government in Khyber Pakhtunkhwa Pakistan would be a huge task with the expected outcome on the world's climate, weather, temperature, protection, and preservation of atmospheric health, reduction in greenhouse gas effects, lowering cases of random floods, lowering rains, and drought. The goal is to plant trees all around the country in the hopes of making a difference in the lives of all living things on the earth (Pirovani et al., 2018). In 2010, Punjab had a natural vegetation of 28.9 kilometers, or 0.14 percent of its entire land. Punjab lost 434 ha of tree cover and $125 \mathrm{kt}$ of $\mathrm{CO}_{2}$ emissions between 2001 and 2020, a 1.2 percent decline in tree cover since 2000. In 2020, it had lost 385 million hectares of forest, equivalent to 156 million tonnes of $\mathrm{CO}_{2}$. Ahmad et al. (2021) evaluated spatial forest in Punjab from 2000 to 2021 and also reported that six remote sensing studies were conducted in various districts of Punjab, showing methods of study and tree plantation data. It is also drawn that
Punjab lost 434 ha of tree cover and $125 \mathrm{kt}$ of $\mathrm{CO}_{2}$ emissions between 2001 and 2020, a 1.2 percent decline in tree cover since 2000.

While as per GFW (2014), between 2004 and 2007, the top two regions in Punjab were responsible for 77 percent of all tree cover loss. Faisalabad is an industrial city with high pollution and smog. It had 16.6 hectares of tree cover in 2010, accounting for 0.00093 percent of the city's total land area. It lost 330 million hectares of forest cover in 2012, equating to 120 tonnes of $\mathrm{CO}_{2}$. Faisalabad added 1 hectare of tree cover in the region from 2001 to 2012, accounting for 1.7 percent of all tree cover gain in Punjab (GFW, 2014). Faisalabad district has a total area of $14,43,703$ acres, with a woodland part of 3890 acres, of which 2290 acres are below district jurisdiction, and the remainder is maintained by the Faisalabad Forest Division (Irshad et al., 2011). Forestry is disappearing at a frightening level. The principal reasons for deterioration are growth, increasing people, excessive use of forest firewood for boiling, furniture, overgrazing, use of wood for petrol, inflexible government plans, and involvement of government officers in selling wood, and rural people dependency on wood. In order to combat the situation under the umbrella of Clean and Green Pakistan, the world record was formed by planting 100,000 saplings simultaneously in the Faisalabad district by the administration and allied departments (Shahid, 2021). In the same context, according to Wajeh Udin (2021), Faisalabad Forest Department completed its $97 \%$ target for monsoon tree plantation throughout the district.

Punjab increased 71 hectares of tree cover between 2001 and 2012, accounting for $8.3 \%$ of total tree cover gains in Pakistan. Natural forest cover accounted for approximately 0.18 percent of Punjab in 2000. Plantations were 18 hectares, natural forest 36.6 Kha, and 20.5 Mha non-forest area. The purpose of the study was to see how successful and efficient the Billion Tree Tsunami Project is in Faisalabad. How Governmental or NonGovernmental sectors work at their level to cultivate trees at the industrial city Faisalabad; where there is no proper system and time to take care or even think about saving and securing trees. To decrease the level of pollution, it is a dire need to implement this billion trees project in the city of Faisalabad. If environment is considered, it is found that most animals are extinct, and others are migrating their habitats to those areas where food, shelter, and a good environment are available in respect of the city. In Faisalabad, the level of pollution and smog is rising every year in the air. The study aims were to analyze the need of the project, participation of the government and non-government sectors, and to find out the involvement of agricultural extension agents.

\section{METHODOLOGY}

The study area, Faisalabad, was well known as one of British India's earliest strategic towns. In 2013, it was 46 percent, compared to 69 percent for males; rural literacy was 49 percent compared to 74 percent in urban regions. Faisalabad is the hub of Pakistan's the literacy rate for females in the Faisalabad textile industry. Faisalabad contributes $5 \%$ of Pakistan's annual GDP. As a result, it is known as Pakistan's Manchester (Sharif, 2012). City Faisalabad was selected purposively due to the number of industries and textiles as 
compared to other cities. The study population includes the school education department, forest department, agriculture extension Faisalabad office, and local communities. Quota sampling was used to draw the sample from three departments and the local community. The study sample contains 50 agricultural extension agents, 33 teachers from 3 government schools, 50 employees from the forest department, and 50 local people. The total sample size was 124 drawn through the survey system website with CI $5 \%$ and CL 95\%. A well-prepared questionnaire was developed to collect data. The research tool (questionnaire) was pretested to check the strength and consistency of the research. Descriptive statistics and gamma coefficient (also called the gamma statistic) were calculated by using SPSS software.

\section{RESULTS AND DISCUSSION}

Table 1 shows the demographic variables such as gender, age, qualification, and marital status. Young people are thought to be more adaptable to change, with more exposure to and use of agricultural suggestions than older people (Ramachandran, 2007). In Table 1 , in the context of qualification mean $=2.40$ and $\mathrm{SD}=0.892$ mark that predominately respondents were graduate in education regarding age 2.19 mean and the standard deviation is 0.985 shows young to middle-aged respondents participated in the study.

Table 1. Distribution of respondents according to their demographic variables.

\begin{tabular}{lcc}
\hline Demographic variables & Mean & S.D \\
\hline Qualification & 2.40 & .892 \\
Age & 2.19 & .985 \\
Gender & 1.34 & .475 \\
Marital status & 1.31 & .466 \\
\hline
\end{tabular}

Table 2. Distribution of the respondents according to reshaped environmental strategies in BTTP.

\begin{tabular}{|c|c|c|c|c|}
\hline Reshaped Strategies for the Environment & Mean & S.D & $\begin{array}{l}\text { Weighted } \\
\text { Score }\end{array}$ & $\begin{array}{l}\text { Rank } \\
\text { order }\end{array}$ \\
\hline Improve water storage capacity & 3.95 & .927 & 490 & $1 \mathrm{st}$ \\
\hline Sustain ecosystem & 3.72 & .984 & 461 & 2nd \\
\hline Oxygen Production & 3.70 & 1.074 & 459 & $3 r d$ \\
\hline Control the pollution & 3.69 & 1.122 & 457 & 4 th \\
\hline Control temperature & 3.65 & .912 & 452 & 5 th \\
\hline Soil conservation & 3.65 & .981 & 452 & 5 th \\
\hline Sustainable environment & 3.65 & .930 & 452 & 5 th \\
\hline Improve the quality of the environment & 3.64 & 1.069 & 451 & 6th \\
\hline To mitigate the impact of climate change & 3.62 & .916 & 449 & 7 th \\
\hline Support in the Climate Change Conservation & 3.59 & 1.036 & 445 & 8th \\
\hline Soil cleanliness & 3.57 & .947 & 443 & 9th \\
\hline Provision of habitat & 3.54 & 2.914 & 439 & 10th \\
\hline Canals side plantation & 3.48 & 1.047 & 431 & 11 th \\
\hline Help in Conservation on Biodiversity & 3.47 & .958 & 430 & 12th \\
\hline Control Soil erosion & 3.46 & 1.031 & 429 & 13th \\
\hline Planting trees & 3.44 & 1.143 & 427 & 14 th \\
\hline $\begin{array}{l}\text { Protecting downstream agriculture and infrastructure from flood damage } \\
\text { by preventing soil erosion and reservoir siltation }\end{array}$ & 3.43 & .989 & 425 & 15 th \\
\hline Promote the dwindling local flora /tree species & 3.43 & .956 & 425 & 15 th \\
\hline Act as wind-breakers & 3.40 & .855 & 422 & 16 th \\
\hline Roads side plantation & 3.40 & 1.110 & 421 & 17 th \\
\hline Slow down the stormwater run-off & 3.34 & .979 & 414 & 18th \\
\hline Protective measures after plantation & 3.27 & 1.092 & 406 & 19th \\
\hline Control wind erosion & 3.23 & .900 & 400 & 20th \\
\hline Works for the protection of soil from rain & 3.19 & 1.057 & 396 & $21 s t$ \\
\hline Protection mechanism from plant diseases & 3.19 & 1.072 & 396 & $21 s t$ \\
\hline
\end{tabular}

The category of gender mean $=1.34$ and mean $=0.475$ showed higher male gender participation in the study. In the end, the marital status shows a mean of 1.31 , and the standard deviation is .466 implies that the majority were married. The demographic attributes of the respondents are effective for the behavior of the respondents to provide precise data.
Table 2 shows, the reshaped environmental strategies in BTTP consist of different attributes. These attributes show the mean, standard deviation, weighted score, and ranked order. The attribute of improved water storage capacity shows the mean is 3.95 , the standard deviation is .927 , and show the weighted score is 490 and lies the $1^{\text {st }}$ rank. The attribute of control 
temperature shows the mean is 3.65 , the standard deviation is .912 , and the weighted score is 452 and lies the $5^{\text {th }}$ rank in order. The attribute of provision of habitat shows the mean is 3.54 , the standard deviation is 2.914 , and the weighted score is 439 and lies the $10^{\text {th }}$ ranked in order. The attribute of work for the protection of soil from rain and protection mechanism from plant diseases show the mean is 3.19 , the standard deviation is 1.057 , and the weighted score is 396 and falls in the $21^{\text {st }}$ ranked. The billion tree tsunami project has all the above-mentioned targets; the glimpses are shown by Wajeh Udin (2021) as 97\% target for tree plantation is achieved throughout the district.

Table 3 shows, the reshaped strategies for livelihood in BTTP consist of different attributes. These attributes show the mean, standard deviation, weighted score, and ranked order. The attribute of Labour opportunity shows the mean is 3.70, the standard deviation is 1.074 , and the weighted score is 459 and falls in a $1^{\text {st }}$ rank in order. While Forest department boost up got the second position with mean 3.69 and SD 1.12. The attribute of allocating funding shows the mean is 3.60 , the standard deviation is .918 , and the weighted score is 447 , and the lie in a $6^{\text {th }}$ ranked. The attribute of seed provision shows the mean is 3.40 , the standard deviation is 1.089 , and the weighted score is 422 and falls in a $15^{\text {th }}$ rank in order. The attribute of increased property value shows the mean is 3.11 , the standard deviation is 1.149. It can be deduced that overall, tree plantation raised the income of local people, labour force, transporter. At the same time, impacts are long-lasting, including the provision of timber and fuelwood, herbal medicines, and improving forage for livestock (Chowdhury, 2010).

Table 3. Distribution of the respondents according to reshaped livelihood strategies in BTTP.

\begin{tabular}{|c|c|c|c|c|}
\hline Reshaped strategies for livelihood & Mean & S.D & $\begin{array}{l}\text { Weighted } \\
\text { Score }\end{array}$ & $\begin{array}{l}\text { Rank } \\
\text { order }\end{array}$ \\
\hline Labour opportunity & 3.70 & 1.074 & 459 & $1 \mathrm{st}$ \\
\hline Forest department boost up & 3.69 & 1.122 & 457 & 2nd \\
\hline Income generation for Transportation companies & 3.65 & .912 & 452 & $3 \mathrm{rd}$ \\
\hline Employment opportunities & 3.65 & .981 & 452 & $3 \mathrm{rd}$ \\
\hline Moderating harsh climate improved productivity & 3.62 & .916 & 449 & 4 th \\
\hline $\begin{array}{l}\text { Provide and protect animal habitat, as well as manage national wildlife parks, } \\
\text { sanctuaries, and biosphere reserves }\end{array}$ & 3.61 & .935 & 448 & 5 th \\
\hline Allocate funding & 3.60 & .918 & 447 & 6 th \\
\hline Raised awareness among students, teachers and society & 3.57 & .947 & 443 & 7 th \\
\hline Provision of habitat & 3.54 & 2.914 & 439 & 8th \\
\hline Training regarding tree plantation & 3.52 & .992 & 437 & 9th \\
\hline Increase the pasture's productivity and other related services and function & 3.48 & 1.000 & 432 & 10th \\
\hline Control Soil erosion & 3.46 & 1.031 & 429 & 11 th \\
\hline $\begin{array}{l}\text { Increase the productivity of forestlands by producing timber, fuel, and other } \\
\text { multipurpose tree species }\end{array}$ & 3.45 & .905 & 428 & 12 th \\
\hline Enhance the protective roles of watersheds in terms of water regime regulation & 3.44 & .998 & 427 & 13th \\
\hline $\begin{array}{l}\text { Protecting downstream agriculture and infrastructure from flood damage by } \\
\text { preventing soil erosion and reservoir siltation }\end{array}$ & 3.43 & .989 & 425 & 14th \\
\hline Seed provision & 3.40 & 1.089 & 422 & 15 th \\
\hline Roads side plantation & 3.40 & 1.110 & 421 & 16th \\
\hline Increase in income of local people & 3.38 & .976 & 419 & 17 th \\
\hline Slow down the storm water run-off & 3.34 & .979 & 414 & 18th \\
\hline Raised income for nursery grower & 3.26 & 1.118 & 404 & 19th \\
\hline Control wind erosion & 3.23 & .900 & 400 & 20th \\
\hline Provide land & 3.19 & 1.214 & 396 & $21 \mathrm{st}$ \\
\hline Fertilizer provision & 3.12 & 1.130 & 387 & 22nd \\
\hline Increased property value & 3.11 & 1.170 & 386 & 23rd \\
\hline
\end{tabular}

\section{Construction of Dependent Variable (Impact of Billion- Tree Tsunami Project)}

The dependent variable (Impact of billion-tree tsunami project) was measured by using a 5-point Likert scale with 12 statements. To investigate the combined effect of entire statements (variables) in predicting the response variable, all the statements in matrix questions are combined to form a single prime or main variable known as an index variable. However, before the development of the index variable, it is a prerequisite to ensure the element of consistency among all the items in the matrix question. For this purpose, a reliability check is carried out, and the value of Cronbach Alpha is determined. The value of Cronbach
Alpha is .701. It means the dependent variable is reliable. Table 4 represents the relation between the age of the respondents and their perception of the impact of the billion-tree tsunami project. The Chi-square coefficient displays a non-significant $(\chi 2=4.67, p$ $=.586$ ) association among the age of the respondents and their perception about the impact of the billion tree tsunami project. Gamma statistic $(\lambda=-0.029, p=.824)$ also showing insignificant relation among the variables. It means, every age group had almost the same perception of the impact of the billion trees tsunami project.

Table 5 represents the relation between the qualification of the respondents and their perception of the impact of the 
billion-tree tsunami project. The Chi-square coefficient displays a significant $(\chi 2=15.65, p=.004)$ association among the qualification of the respondents and their perception about the impact of the billion tree tsunami project. Gamma statistic $(\lambda=0.344, p=.010)$ show a significant and positive relation among the variables. It tells that the majority of the highly qualified (postgraduation and above) had the more positive opinion that impact of billion tree tsunami project as compared to those respondents who had below graduation level education.

Table 4. Relationship between the age of the respondents and their perception about the impact of billion tree tsunami project.

\begin{tabular}{|c|c|c|c|c|}
\hline \multirow{2}{*}{ Age (in years) } & \multicolumn{3}{|c|}{ Impact of billion tree tsunami project } & \multirow{2}{*}{ Total } \\
\hline & Low & Medium & High & \\
\hline \multirow{2}{*}{25 to 30} & 9 & 16 & 10 & 35 \\
\hline & $25.7 \%$ & $45.7 \%$ & $28.6 \%$ & $100.0 \%$ \\
\hline \multirow{2}{*}{31 to 35} & 9 & 28 & 8 & 45 \\
\hline & $20.0 \%$ & $62.2 \%$ & $17.8 \%$ & $100.0 \%$ \\
\hline \multirow{2}{*}{36 to 40} & 8 & 17 & 4 & 29 \\
\hline & $27.6 \%$ & $58.6 \%$ & $13.8 \%$ & $100.0 \%$ \\
\hline \multirow{2}{*}{ Above 40} & 3 & 7 & 5 & 15 \\
\hline & $20.0 \%$ & $46.7 \%$ & $33.3 \%$ & $100.0 \%$ \\
\hline \multirow{2}{*}{ Total } & 29 & 68 & 27 & 124 \\
\hline & $23.4 \%$ & $54.8 \%$ & $21.8 \%$ & $100.0 \%$ \\
\hline Chi-square $=4.67 ;$ d.f. $=6$ & & & P-value $=.586 \mathrm{NS}$ & \\
\hline $\operatorname{Gamma}(\lambda)=-0.029$ & & & $\mathrm{P}$-value $=.824 \mathrm{NS}$ & \\
\hline
\end{tabular}

Table 5. Relationship between the qualification of the respondents and their perception about the impact of billion tree tsunami project.

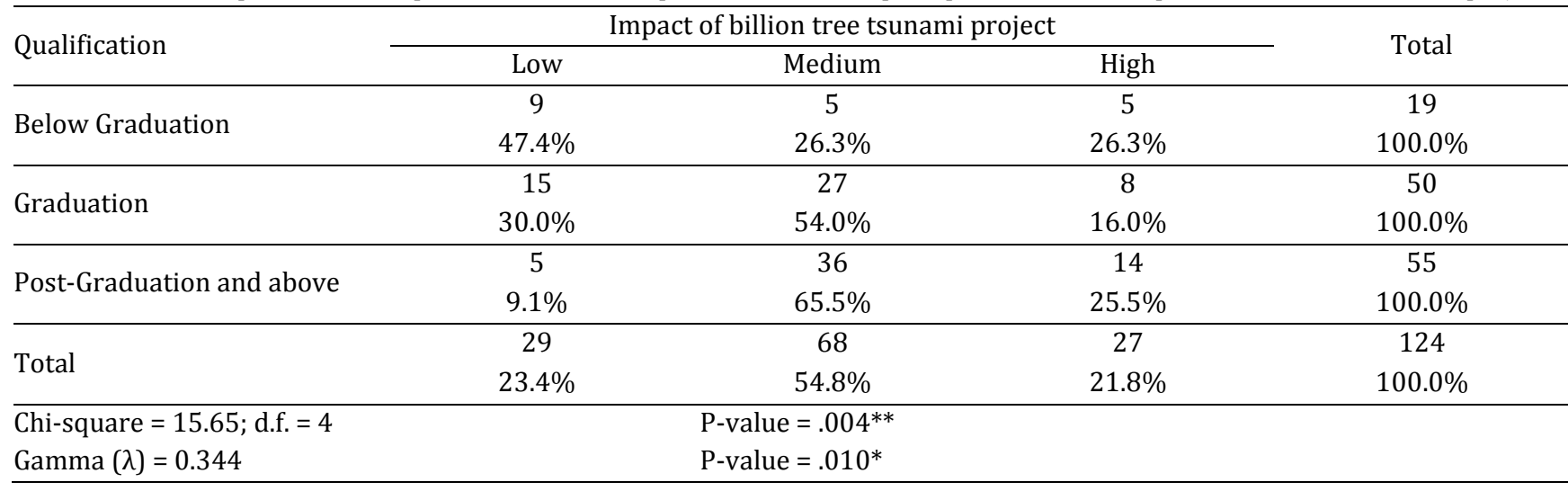

This is evident from the findings; below graduation respondents had low (47.4\%), medium (26.3\%), and high (26.3\%) level perceptions about the impact of the billion tree tsunami project. However, highly qualified (post-graduation and above) respondents observed low (9.1\%), medium (65.5\%), and high $(25.5 \%)$ level impact of the billion tree tsunami project.

\section{CONCLUSIONS}

It was concluded that the Billion-tree project plays a vital role in the provision of availability of wages for the unemployed laborers and certain jobs for the farmers in the development of nurseries. Meanwhile, this project became a great source of earning. The basic need of the program was to improve water storage capacity, sustain the environment and oxygen production. The role of the government was to develop nurseries and allocate funding. Agricultural extension agents highly participated in creating green Pakistan. The teacher's role in BTTP was plant protection and sustainability, and the multi-sectoral effect was to increase the income of people. This project generates great motivation to take part in the plantation of trees; thus, the main impact of this project was to reduce pollution levels, lower deforestation, and help in the afforestation of forests. These all efforts had a positive effect on our surrounding environment. This project generates great motivation to take part in the plantation of trees; thus, the main impact of this project was that it reduced pollution levels, lowered deforestation, and helped in the afforestation of forests. These all efforts had a positive effect on our surrounding environment. The study gives way forward for the policymakers to endorse and continue this project and to start other projects like this to improve the environment and cleanliness of the air for the people. Such projects can also have effects on the livelihood of the people.

\section{REFERENCES}

Ahmad, A., Ahmad, S.R., Gilani, H., Tariq, A., Zhao, N., Aslam, R.W., Mumtaz, F., 2021. A synthesis of spatial forest assessment studies using remote sensing data and techniques in Pakistan. Forests 12, 1211.

Ahmad, A., Shahbaz, B., Shehzad, M., Khursheed, K., Aftab, M., 2017. Analysis of performance of farm forestry and its role in household income in district Faisalabad, Pakistan. J Glob. Innov. Agric. Soc. Sci. 5, 39-42. 
Angelsen, A., Shitindi, E.F.K., Aarrestad, J., 1999. Why do farmers expand their land into forests? Theories and evidence from Tanzania. Environ. Dev. Econ. 4, 313331.

Ashraf, U., 2019. Exclusion in afforestation projects in Pakistan. Econ. Polit. Wkly. 54, 17-20.

Chowdhury, R.R., 2010. Differentiation and concordance in smallholder land use strategies in southern Mexico's conservation frontier. Proc. Natl. Acad. Sci. 107, 57805785.

Fomete, T., Vermaat, J., 2001. Community forestry and poverty alleviation in Cameroon. Rural Development Network. Network paper 25h.p.9.

GFW, 2014. Global Forest Watch., Retrieved from: https://data.globalforestwatch.org.

Government of KPK, 2015. Billion Tree Tsunami Project in Khyber Pakhtunkhwa, Peshawar, Government of Khyber Pakhtunkhwa, Pakistan.

Irshad, M., Khan, A., Inoue, M., Ashraf, M., Sher, H., 2011. Identifying factors affecting agroforestry system in Swat, Pakistan. African J. Agric. Res. 6, 2586-2593.

Khan, N., Shah, S.J., Rauf, T., Zada, M., Yukun, C., Harbi, J., 2019. Socioeconomic impacts of the billion trees afforestation program in Khyber Pakhtunkhwa Province (KPK), Pakistan. Forests 10, 703.

Kleinn, C., Kändler, G., Schnell, S., 2011. Estimating forest edge length from forest inventory sample data. Can. J. For. Res. 41, 1-10.

Nowak, D.J., Greenfield, E.J., Hoehn, R.E., Lapoint, E., 2013. Carbon storage and sequestration by trees in urban and community areas of the United States. Environ. Pollut. 178, 229-236.

Nunes, A.N., De Almeida, A.C., Coelho, C.O.A., 2011. Impacts of land use and cover type on runoff and soil erosion in a marginal area of Portugal. Appl. Geogr. 31, 687-699.
Panigrahy, R.K., Kale, M.P., Dutta, U., Mishra, A., Banerjee, B., Singh, S., 2010. Forest cover change detection of Western Ghats of Maharashtra using satellite remote sensing based visual interpretation technique. Curr. Sci. 657-664.

Pirovani, D.B., Pezzopane, J.E.M., Xavier, A.C., Pezzopane, J.R.M., de Jesus Júnior, W.C., Machuca, M.A.H., da Silva, S.F., de Almeida, S.L.H., de Oliveira Peluzio, T.M., Eugenio, F.C., 2018. Climate change impacts on the aptitude area of forest species. Ecol. Indic. 95, 405-416.

Ramachandran, N.P.K., 2007. Agroforestry for sustainability of lower-input land-use systems. J. Crop Improv. 19, 25-47.

Selby, A., Petäjistö, L., Koskela, T., 2003. Field afforestation in the context of rural development: a preliminary study of farmers' and rural advisors' perceptions. Metsäntutkimuslaitos. http://urn.fi/URN:ISBN:95140-1871-0

Shahid, S., 2021. World record created by planting 100,000 saplings in Faisalabad. Accessed online from; https://www.aboutpakistan.com.

Sharif, F., 2012. Pakistan's Textile Industry Is Dangerously Fragile. Bloomberg. Retrieved 9 June 2016. https://www.bloomberg.com/news/articles/201204-26/pakistans-textile-industry-is-dangerouslyfragile.

Shinwari, M.I., Khan, M.A., 2000. Vegetation comparison of sacred, reserved and unreserved sites of Rumli Village at Margalla Hills National Park, Islamabad. Pakistan J. Biol. Sci. 3, 1681-1683.

Wajeh Udin, 2021. Agriculture News, Bakhaber Kissan. www. bakhaberkissan.com

Winter, J.C., 2000. Tobacco use by Native North Americans: Sacred smoke and silent killer (Vol. 236). University of Oklahoma Press.

Publisher's note: Science Impact Publishers remain neutral with regard to jurisdictional claims in published maps and institutional affiliations.

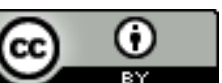

Open Access This article is licensed under a Creative Commons Attribution 4.0 International License, which permits use, sharing, adaptation, distribution and reproduction in any medium or format, as long as you give appropriate credit to the original author(s) and the source, provide a link to the Creative Commons license and indicate if changes were made. The images or other third-party material in this article are included in the article's Creative Commons license, unless indicated otherwise in a credit line to the material. If material is not included in the article's Creative Commons license and your intended use is not permitted by statutory regulation or exceeds the permitted use, you will need to obtain permission directly from the copyright holder. To view a copy of this license, visit https://creativecommons.org/licenses/by/4.0/. 